\title{
Síntese de pigmentos cerâmicos por precipitação química
}

\section{(Synthesis of ceramic pigments by chemical precipitation)}

\author{
R. N. de Almeida , S. F. Santos ${ }^{2}$, J. A. Sampaio ${ }^{1}$, A. B. da Luz LI. Ogasawara $^{2}$, M. C. de Andrade \\ ${ }^{1}$ Centro de Tecnologia Mineral-- CETEM-MCT, Ilha da Cidade Universitária, Av. Ipê, 90 \\ Rio de Janeiro, RJ 21941-590 \\ ${ }^{2}$ PEMM/COPPE/UFRJ - Programa de Engenharia Metalúrgica e de Materiais, \\ Universidade Federal do Rio de Janeiro, C. Universitária, Rio de Janeiro, RJ 21945-970 \\ ${ }^{3}$ Instituto Politécnico, IPRJ/UERJ, Rua Alberto Rangel, s/n, Vila Nova, Nova Friburgo, RJ 28630-050 \\ rnigri@cetem.gov.br,shirleny@metalmat.ufrj.br
}

\begin{abstract}
Resumo
Os pigmentos cerâmicos são substâncias capazes de desenvolver cor em sólido inorgânico (cerâmica ou vidro) quando nele dispersar mantendo-se insolúvel no mesmo, sem reação química com o mesmo, nas elevadas temperaturas de processamento. Óxidos de cobre dão origem a pigmentos verdes que se decompõem em temperaturas relativamente baixas (em torno de $900{ }^{\circ} \mathrm{C}$ ) enquanto adição de outros íons em sua composição poderá melhorar a sua estabilidade térmica e facilitar a sua utilização em revestimentos cerâmicos queimados em altas temperaturas. O presente trabalho teve por objetivo sintetizar, pelo método da precipitação (ou co-precipitação) química, pós de óxidos de cobre e de manganês, tanto puros quanto misturados destinados ao uso em esmaltes decorativos de matriz vítrea. Para tal fim, pó de frita de vidro foi produzido pela fusão de feldspato do Seridó (divisa entre Paraíba e Rio Grande do Norte). Massas selecionadas, 5 a 10\% em peso, de pigmentos foram misturadas com o referido pó de frita e a barbotina resultante foi aplicada sobre a superfície de placas de alumina densa, seguindo-se secagem e queima em escolhidas temperaturas. As cores dos recobrimentos obtidos foram avaliadas por medidas colorimétricas usando o sistema CIEL*a*b* e os resultados variaram em função da composição e teor de pigmentos, bem como da temperatura de queima. Constatou-se que os pigmentos de óxidos puros de cobre e de manganês deram tonalidades mais claras do que aquelas fornecidas pelo pigmento misto de cobre e de manganês.

Palavras-chave: precipitação, pigmento, cerâmica.
\end{abstract}

\begin{abstract}
Ceramic pigments are substances that develop color in inorganic solids (ceramic or glass) into which are capable of dispersing themselves at high processing temperatures without dissolution or chemical reaction. Copper oxides give rise to green pigments that undergo thermal decomposition at relatively low temperatures (about $900^{\circ} \mathrm{C}$ ) and the addition of other ions in its composition may improve its stability and applicability to ceramic tiles fired at higher temperatures. The present work had the objective of synthesizing by chemical precipitation (or co-precipitation) pure and mixed oxides of copper and manganese for decorating ceramic tiles. For that purpose, 5 to 10wt.\% of the ceramic pigment has been mixed to glass frit powder made by using feldspar from Seridó (the border region between Paraiba and Rio Grande do Norte, Brazilian States). The resultant slip was applied on the surface of dense alumina plates and fired at different temperatures. The colors of the coating have been evaluated by using a colorimeter and the result varied with the pigment composition and firing temperature. It was found that coating with pure pigments gave a lighter shade while the coating containing mixed oxides of copper and manganese acquired a darker color.
\end{abstract}

Keywords: precipitation, pigment, ceramic.

\section{INTRODUÇÃO}

Um bom pigmento caracteriza-se por possuir baixa solubilidade nos vidrados, alta estabilidade térmica, resistência aos ataques físicos e químicos de abrasivos, álcalis e ácidos, distribuição granulométrica homogênea e adequadamente baixa e ausência de emissões gasosas no seio dos vidrados, pois provocariam defeitos nos mesmos. Do ponto de vista químico, os pigmentos produzem cor pela ação de um íon cromóforo (comumente metais de transição) que absorve radiação visível de forma seletiva e é estabilizado por mecanismos químicos apropriados para conseguir manter sua ação pigmentante sob condições químicas e de temperatura desfavoráveis [1,2].

Anecessidade de novas cores de pigmentos cerâmicos tem crescido, já que nos últimos anos a indústria cerâmica vem ganhando um espaço cada vez maior no mercado mundial, principalmente em relação a artigos para decoração de ambientes, tanto domésticos quanto comerciais [3]. Entre as cores de pigmentos mais requisitas está o verde, geralmente obtido a partir de compostos de óxido de cobre puro. No entanto estes óxidos apresentam certas desvantagens, já que apresenta decomposição em temperatura ao redor de $900{ }^{\circ} \mathrm{C}$. Desta forma, estudos vem sendo realizados para proporcionar 
a síntese de compostos com outros íons associados ao óxido de cobre, possibilitando também a obtenção de pigmentos com tons diversos para atender a demanda da indústria cerâmica [4]. Para que uma cerâmica atinja as características estéticas adequadas ao uso utiliza-se comumente um revestimento que atua impermeabilizando o suporte. Geralmente esses revestimentos são produzidos com pigmentos e fritas (que são materiais de natureza vítrea preparados por fusão) à base de minerais industriais, cujo constituinte principal é o feldspato [5]. A precipitação química em solução homogênea é uma das técnicas de preparação de pós cerâmicos mais antigas, sendo ainda amplamente utilizada pelo fato do equipamento de laboratório requerido ser relativamente simples, aliado à sua potencialidade no que diz respeito à produção de pós com características ideais e menor consumo de energia e calor do que o método da mistura de pós; apresentam um elevado grau de homogeneidade química e estequiométrica, altos valores dos parâmetros óticos e podem ser finamente particulados dependendo das condições da precipitação. As composições de diferentes solutos em tais soluções são extremamente sensíveis a um número de parâmetros (que devem ser controlados) entre os quais o $\mathrm{pH}$, a temperatura e natureza dos ânions presentes na solução onde a precipitação é efetuada [6].

Um fator limitante desta técnica é a lenta taxa em que costuma ser realizada a reação de precipitação, de modo a assegurar o equilíbrio de solubilidade, uma vez que a tentativa de apressar a adição de reagente pode gerar a formação de complexos solúveis e a não homogeneidade do tamanho das partículas, portanto o efeito oposto ao desejado [6].

O objetivo deste trabalho foi sintetizar pigmentos de óxido de cobre e manganês para a utilização em revestimentos cerâmicos.

\section{MATERIAIS E MÉTODOS}

Foi adicionado o hidróxido de sódio nas soluções contendo íons cobre e manganês para proporcionar as reações químicas. Realizou-se também co-precipitação para obter óxidos mistos, de cobre e manganês. Este processo permite que substâncias solúveis se incorporem aos precipitados durante sua formação e pode-se dar de duas maneiras: por formação de soluções sólidas ou por adsorção na superfície [7]. Essa técnica proporciona a formação de hidróxidos, que necessitam da etapa de calcinação para obter os óxidos desejados.

$\mathrm{Na}$ precipitação homogênea utilizou-se $50 \mathrm{~mL}$ de $\mathrm{CuSO}_{4} \cdot 5 \mathrm{H}_{2} \mathrm{O} 0,1 \mathrm{M} / 50 \mathrm{~mL}$ de $\mathrm{MnSO}_{4} \cdot \mathrm{H}_{2} \mathrm{O}$ 0,1 M com 100 $\mathrm{mL}$ de $\mathrm{NaOH} 0,1 \mathrm{M}$. Na co-precipitação necessitou-se de $50 \mathrm{~mL}$ de $\mathrm{CuSO}_{4} \cdot 5 \mathrm{H}_{2} \mathrm{O} 0,1 \mathrm{M}$ com $50 \mathrm{~mL}$ de $\mathrm{MnSO}_{4} \cdot \mathrm{H}_{2} \mathrm{O}$

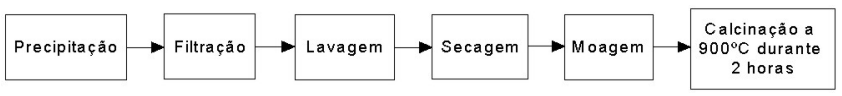

Figura 1: Fluxograma do processo de obtenção do pigmento cerâmico.

[Figure 1: Flow chart of the process of obtaining of the ceramic pigment.].
Tabela I - Composição da frita.

[Table I - composition of the frit.]

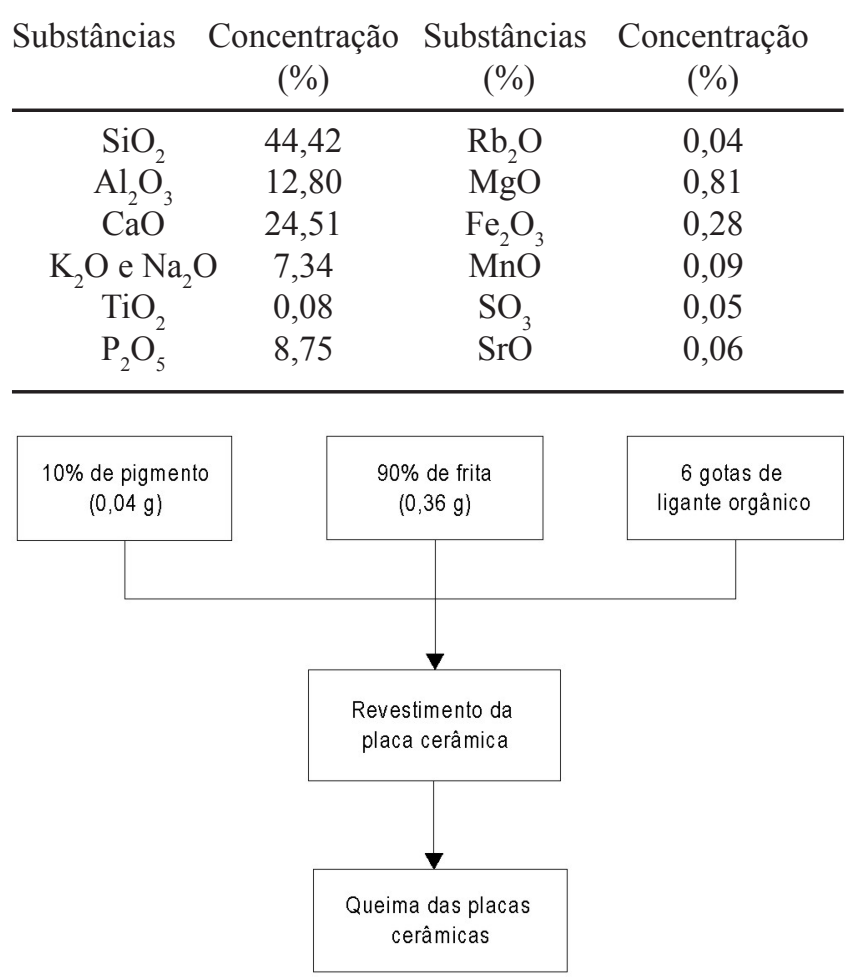

Figura 2: Fluxograma do processo de revestimento da placa cerâmica. [Figure 2: Flow chart of the process of coating of the ceramic plate.]

$0,1 \mathrm{M}$ e $200 \mathrm{~mL}$ de $\mathrm{NaOH} 0,1 \mathrm{M}$. Na etapa seguinte foram efetuadas as operações de filtração, lavagem, secagem, moagem e calcinação a $900{ }^{\circ} \mathrm{C}$ durante $2 \mathrm{~h}$. O processo de síntese do pigmento está esquematizado na Fig. 1.

As suspensões sólidas aquosas, destinadas ao revestimento das placas cerâmicas, foram preparadas misturando-se os pigmentos na frita. Esta foi obtida pela fusão do feldspato (Tabela I) em cadinho de fosfato de cálcio. Na obtenção da frita utilizou-se um maçarico com duas saídas de gás (oxigênio e acetileno), a fim de atingir a temperatura necessária à fusão do mineral industrial. O líquido da fusão foi vertido em água, para proporcionar resfriamento rápido e garantindo uma estrutura amorfa [3].

Os primeiros revestimentos cerâmicos foram compostos de $10 \%$ de pigmento, $90 \%$ de frita e ligante orgânico (seis gotas do ligante orgânico). Esta mistura foi pincelada sobre o substrato. Foram utilizados substratos cerâmicos de alumina densa e as temperaturas de queima foram de 900, 980, $1100 \mathrm{e}$ $1200{ }^{\circ} \mathrm{C}$ durante $30 \mathrm{~min}$. A taxa de aquecimento utilizada foi de $10^{\circ} \mathrm{C} / \mathrm{min}$ e a de resfriamento, $20^{\circ} \mathrm{C} / \mathrm{min}$. O fluxograma do processo de revestimento está esquematizado na Fig. 2.

Foram também preparados revestimentos coma concentração do pigmento diminuída para $5 \%$, já que o custo do pigmento é elevado e a indústria cerâmica costuma utilizar apenas cerca de $3 \%$ de pigmento nos seus revestimentos. Nestes revestimentos utilizou-se somente o pigmento de mistura dos óxidos de cobre e de manganês e a frita composta de feldspato, em diferentes 
temperaturas de queima.

As medidas das cores dos pigmentos sintetizados e dos revestimentos foram feitas utilizando um colorímetro Technidyne, Color Touch 2, Model ISSO, nos padrões CIELAB (iluminante D65 num ângulo de $2^{\circ}$ ). Esse método permite medir a intensidade de absorção na região visível para obtenção dos parâmetros $\mathrm{L}^{*}$, referente à luminosidade [que varia do negro (0) ao branco (100)], a* que é intensidade de cor vermelho (+) / verde (-) e b* a intensidade de cor amarelo (+) / azul (-) [8]. Foram traçadas também as curvas de reflectâncias para cada pigmento e para os revestimentos com o pigmento de óxido misto em diferentes temperaturas de queima.

Análises térmicas (TGA/ATD) foram realizadas em equipamento Shimadzu TA-50WSI (análise termogravimétrica), DTA-50 (análise térmica diferencial) numa taxa de aquecimento de $10{ }^{\circ} \mathrm{C} / \mathrm{min}$ da temperatura ambiente até $1200{ }^{\circ} \mathrm{C}$ em atmosfera oxidante.

\section{RESULTADOS E DISCUSSÃO}

Pode-se constar pelo perfil observado nas curvas de reflectância (Fig. 3) que todos os pigmentos sintetizados apresentaram baixa luminosidade, pois se verificou baixa reflexão em toda a faixa de comprimento de onda do visível, evidenciando a formação de pigmentos em tons escuros. No entanto entre os três pigmentos somente o de óxido misto apresentou um perfil que indicou desenvolvimento de cor amarelada pela significativa reflexão da luz na faixa de comprimento de onda acima de $550 \mathrm{~nm}$ [8].

Quanto aos revestimentos obtidos com o pigmento constituído apenas de óxido de cobre pôde-se constatar que a tonalidade não se alterou muito com o aumento da temperatura de queima, como pode ser observado nas

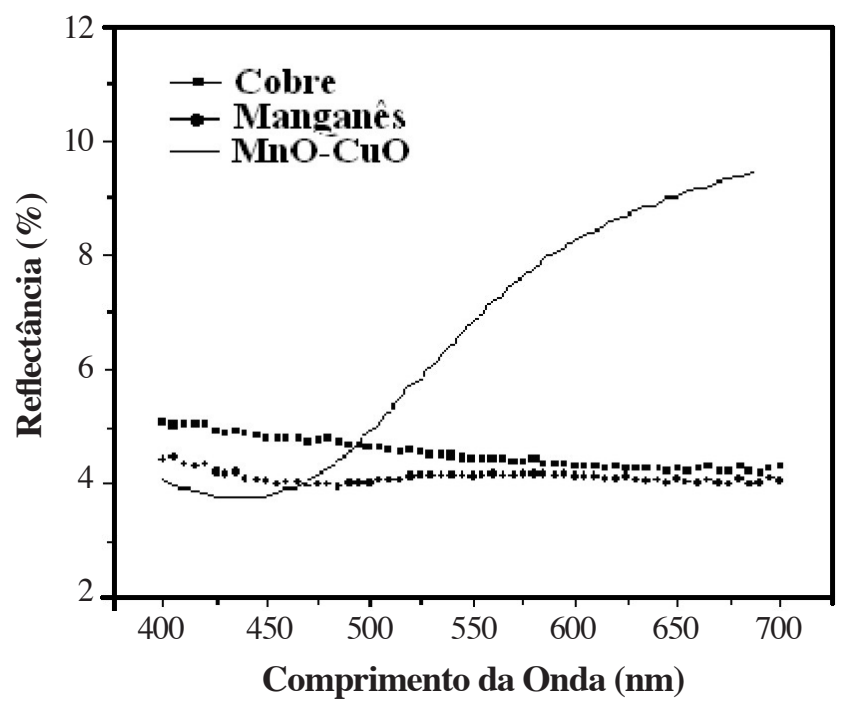

Figura 3: Curvas de reflectância dos três pigmentos sintetizados pelo método de precipitação.

[Figure 3: Reflectance curves of the three pigments synthesized by the precipitation method.]

Tabelas II e III. Cabe ressaltar que apesar da literatura destacar que os compostos de óxido de cobre decompõem-se ao redor de $900{ }^{\circ} \mathrm{C}$, no caso dos revestimentos obtidos neste trabalho, a utilização de fritas possibilitou a manutenção de uma coloração verde-amarelada, mesmo em temperaturas acima de $900{ }^{\circ} \mathrm{C}$, como pode ser observado nas Tabelas II e III, em que predominam valores de $\mathrm{a}^{*}$ negativo ou variando de zero a 3,8 (típico da faixa de coloração verde) e valores de $b^{*}$ sempre positivos indicando a coloração amarela, principalmente nas amostras a $1200^{\circ} \mathrm{C}$ em que a cor amarela

Tabela II - Medidas de cores dos revestimentos cerâmicos contendo $10 \%$ de pigmento e queimados a 900 e $980{ }^{\circ} \mathrm{C}$ durante 30 min. [Table II - Measurements of colors of the ceramic coatings containing $10 \%$ of pigment and fired to 900 and $980{ }^{\circ} \mathrm{C}$ during $30 \mathrm{~min}$.]

\begin{tabular}{lcccccc}
\hline Amostras & \multicolumn{3}{c}{$900^{\circ} \mathrm{C}$} \\
& $\mathrm{L}^{*}$ & $\mathrm{a}^{*}$ & $\mathrm{~b}^{*}$ & $\mathrm{~L}^{*}$ & $\begin{array}{c}9800^{\circ} \mathrm{C} \\
\mathrm{a}^{*}\end{array}$ & $\mathrm{~b}^{*}$ \\
\hline Óxido de cobre + frita & 39,91 & $-0,62$ & 1,34 & 41,05 & 0,71 & 3,30 \\
Óxido de manganês + frita & 29,94 & 2,28 & 4,12 & 26,18 & 2,63 & 4,83 \\
Óxido de cobre e manganês + frita & 32,83 & 0,49 & 0,62 & 36,47 & 0,64 & 2,96 \\
Placa de alumina sem revestimento & 95,05 & $-0,67$ & 1,83 & 95,05 & $-0,67$ & 1,83 \\
\hline
\end{tabular}

Tabela III - Medidas de cores dos revestimentos cerâmicos contendo $10 \%$ de pigmento e queimados a 1100 e $1200{ }^{\circ} \mathrm{C}$ durante 30 min. [Table III - Measurements of colors of the ceramic coatings containing $10 \%$ of pigment and fired at 1100 and $1200{ }^{\circ} \mathrm{C}$ during $30 \mathrm{~min}$.]

\begin{tabular}{lcccccc}
\hline Amostra & \multicolumn{3}{c}{$1100^{\circ} \mathrm{C}$} & \multicolumn{3}{c}{$1200^{\circ} \mathrm{C}$} \\
& $\mathrm{L}^{*}$ & $\mathrm{a}^{*}$ & $\mathrm{~b}^{*}$ & $\mathrm{~L}^{*}$ & $\mathrm{a}^{*}$ & $\mathrm{~b}^{*}$ \\
\hline Óxido de cobre + frita & 37,38 & 0,41 & 2,92 & 43,32 & $-0,32$ & 6,30 \\
Óxido de manganês + frita & 38,92 & 3,83 & 10,41 & 60,89 & 3,83 & 18,94 \\
Óxido de cobre e manganês+ frita & 33,10 & 0,35 & $-0,35$ & 33,72 & 0,02 & 0,61 \\
Placa de alumina sem revestimento & 95,05 & $-0,67$ & 1,83 & 95,05 & $-0,67$ & 1,83 \\
\hline
\end{tabular}


foi predominante. Sugere-se que a partir desta temperatura ocorra reação entre o óxido de cobre e óxidos presentes no revestimento resultando no início da deterioração da coloração apresentada pelos revestimentos.

Para os pigmentos de óxido de manganês puro, constatouse que a diferença de cores dos revestimentos com o aumento da temperatura de queima foi significativa, como pode ser observado com os valores dos parâmetros $\mathrm{L}^{*}, \mathrm{a}^{*} \mathrm{e} \mathrm{b}^{*}$, medidos nas diferentes temperaturas (Tabelas II e III). O valor de $b^{*}$ elevou-se de 4,60 para 18,94, quando a temperatura de queima foi aumentada de 980 para $1200{ }^{\circ} \mathrm{C}$, como também os valores de $L^{*}$ variaram 26,18 para 60,89 , nas mesmas temperaturas,

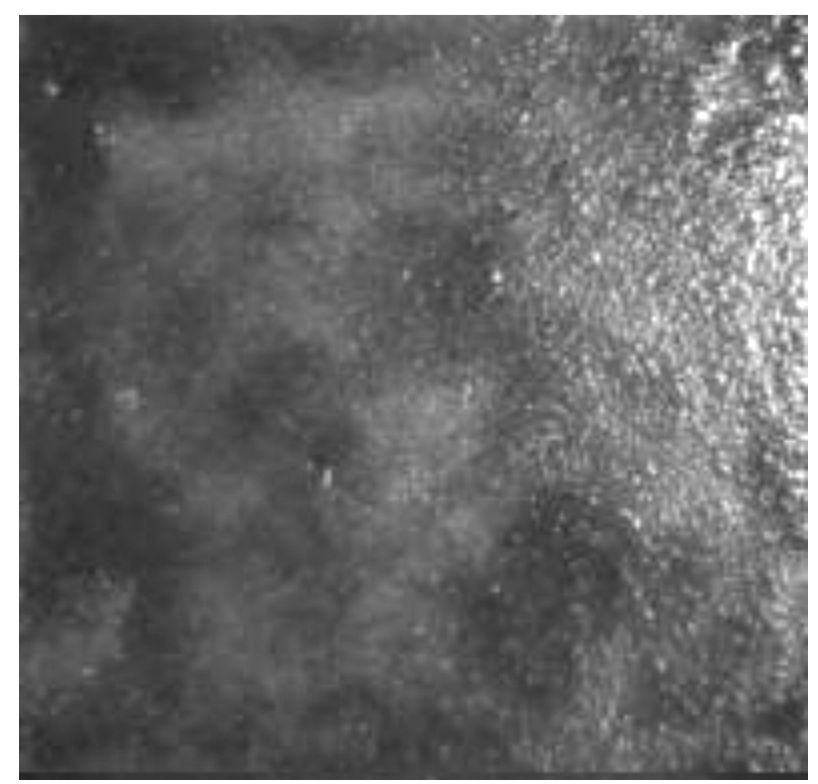

(a) Revestimento queimado a temperatura de $1100^{\circ} \mathrm{C}$

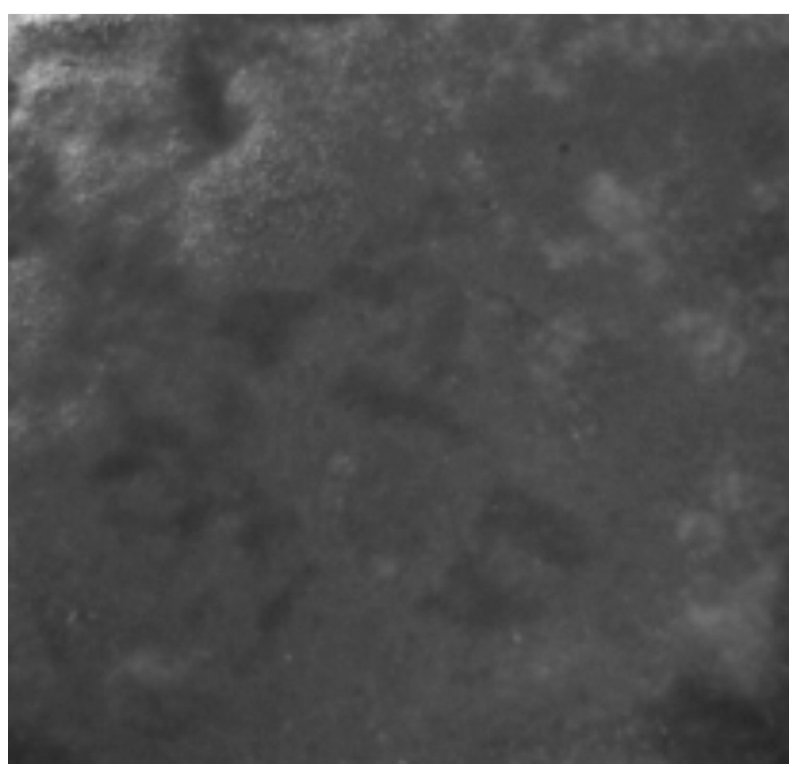

(b) Revestimento queimado a temperatura de $1200^{\circ} \mathrm{C}$

Figura 4: Devitrificação do revestimento obtido com pigmento de mistura de óxidos na temperatura de $1200{ }^{\circ} \mathrm{C}$.

[Figure 4: Devitrification of the coating obtained with pigment of mixture of oxides in the temperature of $1200{ }^{\circ} \mathrm{C}$.] indicando um aumento de luminosidade (que varia de negro (0) ao branco (100)) do revestimento obtido usando apenas óxido de manganês como pigmento. Sugere-se que tenha ocorrido redução do óxido de manganês com mudança de estrutura cristalina, análises de difração de raios X serão realizadas para investigar melhor esta possibilidade.

Devidoà necessidade de novas cores para os revestimentos cerâmicos e de superar o problema da decomposição dos óxidos de cobre, foi realizada a co-precipitação de hidróxidos de manganês e cobre, a fim de testar os revestimentos cerâmicos com os pigmentos destes óxidos mistos de cobre e manganês. Estes pigmentos apresentaram os valores mais constantes de tonalidades nas diferentes temperaturas de queima (Tabelas II e III), principalmente quanto ao parâmetro $\mathrm{a}^{*}$ e à luminosidade; os valores de $\mathrm{a}^{*}$ ficaram em torno $0,45 \mathrm{e}$ os valores de $\mathrm{L}^{*}$ ao redor de 35 , nas temperaturas de queima de $980{ }^{\circ} \mathrm{C}$ e $1100{ }^{\circ} \mathrm{C}$.

Observou-se que o aumento da temperatura tornou os revestimentos mais vítreos, apesar da ocorrência de uma devitrificação parcial nos corpos de prova queimados a $120{ }^{\circ} \mathrm{C}$. Um revestimento bem vítreo ocorreu na temperatura de queima de $1100{ }^{\circ} \mathrm{C}$, enquanto uma devitrificacão parcial foi encontrada em amostra queimada a $1200{ }^{\circ} \mathrm{C}$, como pode ser visto na microscopia ótica da Fig. 4 (aumento de 11 vezes).

A coloração verde-amarelada do pigmento misto no revestimento foi também caracterizada pelas curvas de reflectância nas diversas temperaturas de queima (Fig. 5), obtendo-se uma banda cujo formato é característico da cor verde, mas a região de reflexão se aproxima da faixa do amarelo (580 nm - limite entre comprimento de onda do verde e do amarelo). Pode-se observar que nas temperaturas de queima 980 e $1100{ }^{\circ} \mathrm{C}$ as curvas mostraram uma banda de reflectância bem definida e maior luminosidade, devido a melhor vitrificação do revestimento nesta temperatura que possibilitou melhor exibição da cor desenvolvida. $\mathrm{Na}$ temperatura de $900{ }^{\circ} \mathrm{C}$ o revestimento

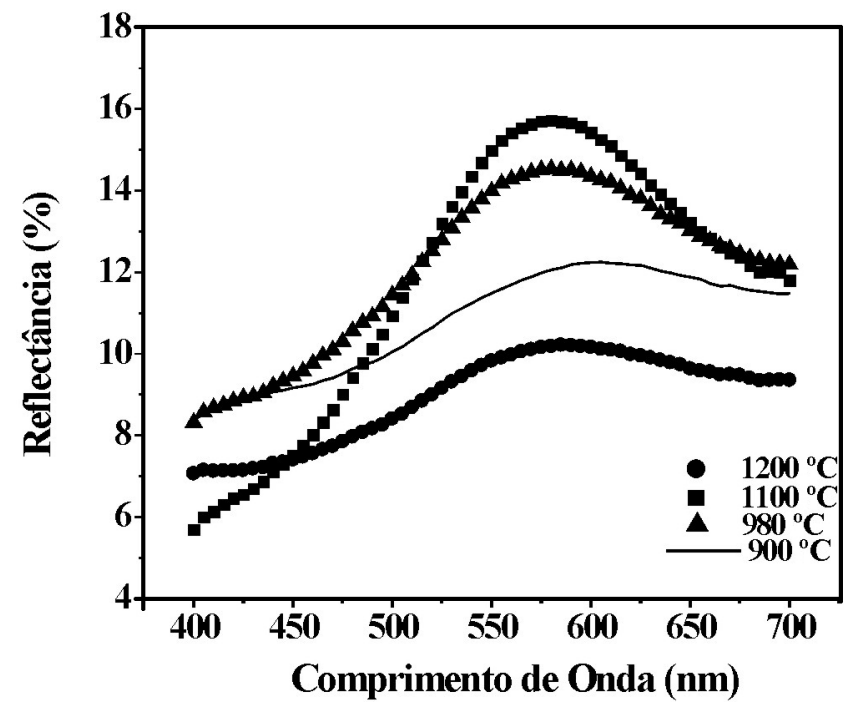

Figura 5: Espectros de reflectância difusa do revestimento obtidos com 5\% do pigmento de mistura do óxido de manganês e cobre.

[Figure 5: Diffuse reflectance spectra of the coating obtained with $5 \%$ of the pigment of manganese and copper oxides.] 
Tabela IV - Medidas de cores dos revestimentos contendo $5 \%$ do pigmento misto de óxidos de cobre e de manganês nas temperaturas de queima de $900,980,1100$ e $1200{ }^{\circ} \mathrm{C}$

[Table I V-Measurements of colors of the ceramic coatings containing of 5\% of the pigment of copper and manganese oxides in the firing temperatures of 900, 980, 1100 and $1200{ }^{\circ} \mathrm{C}$.]

\begin{tabular}{rccccc}
\hline \multicolumn{3}{c}{$900{ }^{\circ} \mathrm{C}$} & \multicolumn{3}{c}{$980{ }^{\circ} \mathrm{C}$} \\
\hline $\mathrm{L}^{*}$ & $\mathrm{a}^{*}$ & $\mathrm{~b}^{*}$ & $\mathrm{~L}^{*}$ & $\mathrm{a}^{*}$ & $\mathrm{~b}^{*}$ \\
40,25 & 0,23 & 6,44 & 43,71 & $-1,83$ & 10,71 \\
\hline & $1100^{\circ} \mathrm{C}$ & \multicolumn{4}{c}{$1200^{\circ} \mathrm{C}$} \\
\hline $\mathrm{L}^{*}$ & $\mathrm{a}^{*}$ & $\mathrm{~b}^{*}$ & $\mathrm{~L}^{*}$ & $\mathrm{a}^{*}$ & $\mathrm{~b}^{*}$ \\
44,41 & $-3,64$ & 18 & 37,14 & $-0,73$ & 6,99 \\
\hline
\end{tabular}

não encontra-se totalmente vitrificado e a $1200{ }^{\circ} \mathrm{C}$ ocorreu a devitrificação na superfície do revestimento o que ocasionou a presença de perfis com menor intensidade de reflectância nestas temperaturas.

A mesma observação foi constatada quando se avaliaram os valores das cores dos revestimentos nas diversas temperaturas de queima, ilustrado na Tabela IV, onde o aumento da temperatura de queima acarretou aumento dos valores de $b^{*}$ e decréscimo dos valores de $\mathrm{a}^{*}$, na queima a $1200^{\circ} \mathrm{C}$ os valores encontrados se reaproximam aos da queima a $900^{\circ} \mathrm{C}$.

Analisando o comportamento térmico do pigmento de óxido misto de cobre e manganês, pode-se constatar que ocorre uma perda de massa de cerca de $8 \%$, a maior parte abaixo de 940 ${ }^{\circ} \mathrm{C}$ e que na análise térmica diferencial foi observado um pico endotérmico ao redor $150{ }^{\circ} \mathrm{C}$, relacionado à liberação de água e dois picos endotérmicos em torno de 830 e $1130{ }^{\circ} \mathrm{C}$ que podem ser relacionados à reações de óxido-redução e de decomposição, respectivamente [9, 10] (Fig. 6). Embora na análise térmica tenham sido observados picos relacionados à decomposição do pigmento, nos revestimentos obtidos o tom manteve-se em temperaturas elevadas. Logo, é importante ressaltar a caracterização dos pigmentos após a aplicação nos revestimentos cerâmicos, pois o comportamento de cada pigmento está sempre muito associado à frita utilizada (à composição da frita, à origem dos minerais industriais utilizados, às condições do processamento, entre outros). Assim um pigmento terá aplicação industrial ou não, somente após a observação deste no revestimento.

\section{CONCLUSÕES}

Pigmentos verde-amarelados de óxido de cobre, óxido de manganês e óxido misto de cobre e manganês foram sintetizados por meio do método de co-precipitação. Os pigmentos foram aplicados a fritas transparentes e verificouse a estabilidade da cor em temperaturas acima de $900{ }^{\circ} \mathrm{C}$. $\mathrm{O}$ pigmento de óxido de manganês foi o que apresentou a maior variação de tonalidade com aumento da temperatura possivelmente devido à ocorrência de reações de redução. A cor dos pigmentos pôde ser cientificamente caracterizada por

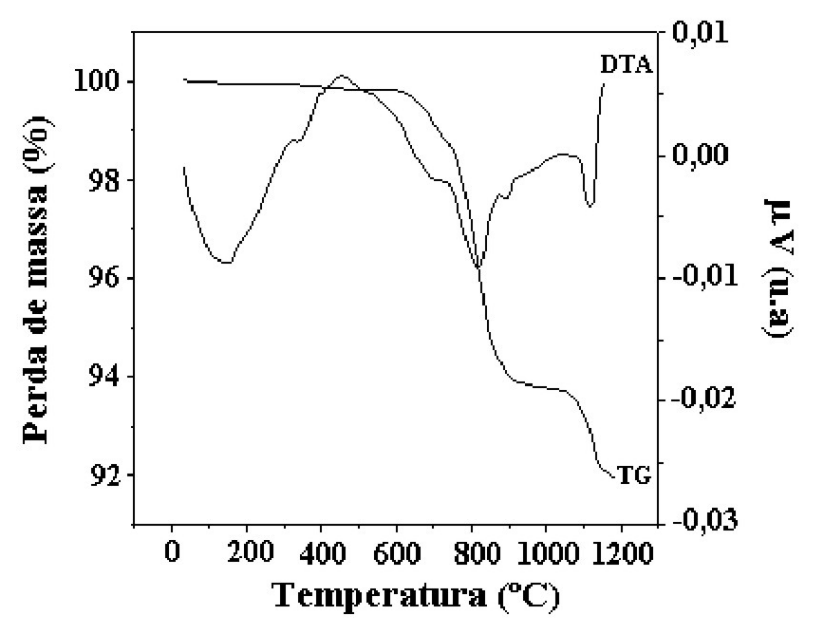

Figura 6: Análise térmica do pigmento sintetizado por coprecipitação do óxido de cobre e manganês.

[Figure 6: Thermal analysis of the pigment synthesized by coprecipitation of the copper and manganese oxide.]

medidas de cor e análise das curvas de reflectância. Verificouse que a utilização da frita tem um papel fundamental para manter os pigmentos estáveis nos revestimentos em elevadas temperaturas.

\section{AGRADECIMENTOS}

Ao CNPq e Faperj pelo apoio financeiro e ao CETEM pela estrutura laboratorial na realização deste trabalho, e à Saint Gobain pelo fornecimento das placas de alumina densa.

\section{REFERÊNCIAS}

[1] F. C. Pícon, S. Cava, E. Leite, E. Longo, Anais do $16^{\circ}$ Congresso Brasileiro de Engenharia e Ciência dos Materiais, S. Carlos, Brasil (2002).

[2] V. P. Della, J. A. Junkes, I. Kunh, H. G. Hiella, D. Hotza, Cerâmica 51, 318 (2005) 111.

[3] F. Bondioli, T. Manfredini, C. Siligardi, J. Am. Ceram. Soc. 88 (2005) 1070.

[4] F. Fernández, C. Colón, A. Duran, R. Barajas, A. d'Ors, M. Becerril, J. Llopis, S. E. Paje, R. Sáez-Puche, I. Julián, J. Alloys \& Comp. 275 (1998) 750.

[5] E. Sanches, Cerâm. Ind. 2 (1997) 32.

[6] K. W. Milanez, Diss. Mestrado, Universidade Federal de Santa Catarina (2003).

[7] D. A. Skoog, D. M. West, F. J. Holler, Fundamentals of Analytical Chemistry, $1^{\text {st }}$ Ed., Saunders College Publishing (1996) cap. 5.

[8] J. Popson, D. D. Malthouse, Measurement and control of the optical properties of paper, $2^{\text {nd }}$ Ed., New Albany, Ninth Publication Copyright (1996).

[9] P. J. Haines, Principles of thermal analysis and calorimetry, $1^{\mathrm{a}}$ Ed., Royal Society of Chemistry (2002).

[10] D. L. Skoog, J. J. Leary, Principles of instrumental analysis, $4^{\mathrm{a}}$ Ed., New York (1992).

(Rec. 28/04/2006, Rev. 01/08/2006, Ac. 01/09/2006) 